\title{
Impact of socioeconomic and demographic factors on reproductive tract infections during reproductive age group (18-45) years
}

\author{
Vasudha Sawant ${ }^{1}$, Sreesti Jaiswal2,", Manjiri Desai ${ }^{3}$ \\ ${ }^{1}$ Associate Professor, ${ }^{2}$ Juniour Resident, ${ }^{3}$ Assistant Professor, Dept. of Obstetrics \& Gynecology, Dr. D.Y. Patil University, \\ Kolhapur, Maharashtra, India
}

*Corresponding Author:

Email: dimpy2410@gmail.com

Received: $15^{\text {th }}$ March, 2018

Accepted: $16^{\text {th }}$ April, 2018

\begin{abstract}
Introduction: The Aims of this study were to identify the prevalence of reproductive tract infection in married women of reproductive age group (18-45 years), to analyse the impact of socioeconomic and demographic factors on reproductive tract infections, to treat the underlying cause.

Materials and Methods: Total of 500 women were examined, out of those 300 women was found to have reproductive tract infections and were enrolled for further study and evaluation. Appropriate antibiotics were given to them and then followed.

Results: The study results showed a high prevalence of RTI (60\%). The highest prevalence was found among the age group between 26-29years followed by 30-33years and 34-37 years. The most affected women were from rural population (80\%), low socioeconomic group $(63.4 \%)$ and illiterate $(59 \%)$.

Conclusion: The present study showed high prevalence of RTI. It needs further depth study on their literacy and economic factors to evaluate and analyse the impact of these factors on reproductive tract infections.
\end{abstract}

Keywords: Reproductive tract infection, Socioeconomic, Demographic, Symptoms.

\section{Introduction}

Reproductive tract infections/ sexually transmitted infections and non-sexually transmitted infections have become a global threat to the health of the population. Genital tract infection can lead to pelvic inflammatory diseases, infertility and ectopic pregnancy \& viral infections are liable to cause vulval \& cervical cancer. ${ }^{1}$ Reproductive tract infections affect both women and men. Research shows that women are more susceptible than men. In India self reported morbidity vary between $39-84 \% \%^{2,3}$ About 490 million cases of reproductive tract infection occur throughout the world of which 79 million cases occur in India annually ${ }^{4}$ sexually transmitted RTIs/STIs are the major reproductive health problems in India. Varieties of organism are involved in causing RTI. A risk of transmission of HIV infection is associated with infections leading to genital ulcer. In developing countries RTIs are responsible for psychological and emotional disturbances as well social \& economical stigmas. ${ }^{5,6}$ In many cases RTIs remain asymptomatic, this causes difficulty in detection and delay in diagnosis and treatment.

Obstetric complications include repeated pregnancy losses intrauterine fetal death, neonatal eye and throat infection, septicaemia.

Majority of complication can be prevented if the women approach to health care provider at the earliest.

\section{Aims and Objectives}

1. To identify the prevalence RTI among married women of reproductive age group (18-45yrs) both pregnant and non pregnant.
2. To observe and analyse, the influence of socioeconomic, socio demographic variable on RTI.

3. To evaluate and assess its effect on routine life.

4. To treat the underlying cause.

\section{Materials and Methods}

This study was undertaken in teaching, tertiary care Hospital, Kolhapur, Maharashtra. The women of reproductive age group (18-49 years) attending Obst Gynec OPD for various complaints were enrolled in the study. About 500 patients coming for Obst Gynaec OPD for any other check up and treatment between Feb 2017 to Aug 2017 were included in the study. It was an observational study. All Married women between the age group of 18-45y coming for Obst and Gyn complaints was asked detailed history, sometimes by asking leading question. Complaints related to RTIs \& STIs were noted.

All women were interviewed about their socioeconomic \& socio demographic, obstetric history, menstrual history, present and previous RTI symptoms. Their general physical examination and other systemic exam was carried out. In OPD per speculum examination was done, any discharge in the vagina noted, its colour, amount, foul smell was evaluated. By doing per vaginal exam any tenderness in the vaginal walls and fornices, any palpable mass was noted. The women who were suspected having infection clinically, wet mount, gram staining of vaginal discharge was carried. In all women urine routine microscopic examination was done. Also their serum VDRL test 
was done. The complete history of each patient was then analysed.

\section{Statistical Analysis}

Graphs are prepared in MS Excel 2007.

All the qualitative variables are compared by using Chi square test. Probability value $(\mathrm{P}<0.05)$ is considered statistically significant. Graphpad quickcal software is used for analysis.

\section{Observations and Results}

A total of 500 patients were interviewed and undergone clinical evaluation, laboratory investigations

Table 1: Prevalence of RTI ( $=300)$

\begin{tabular}{|c|c|c|}
\hline Total number of cases & No of RTI Cases & Prevalence of RTI \\
\hline 500 & 300 & $60 \%$ \\
\hline
\end{tabular}

Amongst those 300 patients were diagnosed as having RTI clinically. The present study showed $60 \%$ prevalence of RTI. Those patients only were included in the study and further evaluated. The majority of age group involved was between the age 26-29 years which was contributing about $32 \%$ followed by the age group of 30-33 year which was about $28 \%$. The lesser affected (2\%) group was between the age 18-21 years.

\section{Table 2: Age wise distribution of RTI cases}

\begin{tabular}{|l|c|c|}
\hline \multicolumn{1}{|c|}{ Age GP } & \% & $\begin{array}{c}\text { No of Cases } \\
(\mathbf{N = 3 0 0 )}\end{array}$ \\
\hline $18--21$ & 2 & 6 \\
\hline $22--25$ & 10 & 30 \\
\hline $26--29$ & 32 & 96 \\
\hline $30--33$ & 28 & 84 \\
\hline $34--37$ & 18 & 54 \\
\hline $38--41$ & 5 & 15 \\
\hline $42--45$ & 5 & 15 \\
\hline Total & 100 & 300 \\
\hline (P<0.0001) & & \\
\hline
\end{tabular}

By CHI Square test incidence of RTI is significantly more in age groups between 26-29 years, 30-33years and 34-37years respectively.

Table 3: Socioeconomic and demographic data

\begin{tabular}{|l|c|c|c|}
\hline \multicolumn{1}{|c|}{ Variable } & $\begin{array}{c}\text { No of Cases } \\
(\mathbf{n = 3 0 0})\end{array}$ & $\mathbf{\%}$ & P value \\
\hline Residence & & & \\
\hline Rural & 240 & 80 & $\left(\mathrm{P}<.0001^{* *}\right)$ \\
\hline Urban & 60 & 20 & \\
\hline Literacy & & & \\
\hline Literate & 122 & 41 & $\mathrm{P}=.0012^{*}$ \\
\hline Illiterate & 178 & 59 & \\
\hline Occupation & & & \\
\hline Housework & 240 & 80 & $\left(\mathrm{P}<.0001^{* *}\right)$ \\
\hline Job/buisiness & 60 & 20 & \\
\hline $\begin{array}{l}\text { Monthly } \\
\text { income }\end{array}$ & & & \\
\hline$<10000$ & 190 & 63.4 & $\left(\mathrm{P}<.0001^{* *}\right)$ \\
\hline$>10000$ & 110 & 36.6 & \\
\hline
\end{tabular}

Among the study population $80 \%$ were residing in rural area, shows that significantly higher incidence of RTI in rural population as compared to urban population. Regarding literacy, the study population suffering from RTI was $59 \%$ illiterate, that means illiterate women due to lack of knowledge related to genital hygiene suffer from RTI.

Further there is significantly higher incidence of RTI among low socioeconomic group $63.4 \%$.

Table 4: Clinical symptoms

\begin{tabular}{|l|c|c|}
\hline & $\%$ & $\begin{array}{c}\text { No of Cases } \\
(\mathbf{n = 3 0 0})\end{array}$ \\
\hline Backache & $26.67 \%$ & 80 \\
\hline Vaginal discharge & $23.33 \%$ & 70 \\
\hline Low abdominal pain & $21.67 \%$ & 65 \\
\hline Itching around Vag area & $13.33 \%$ & 40 \\
\hline Burning micturition & $8.33 \%$ & 25 \\
\hline Dysparunia & $4 \%$ & 12 \\
\hline
\end{tabular}

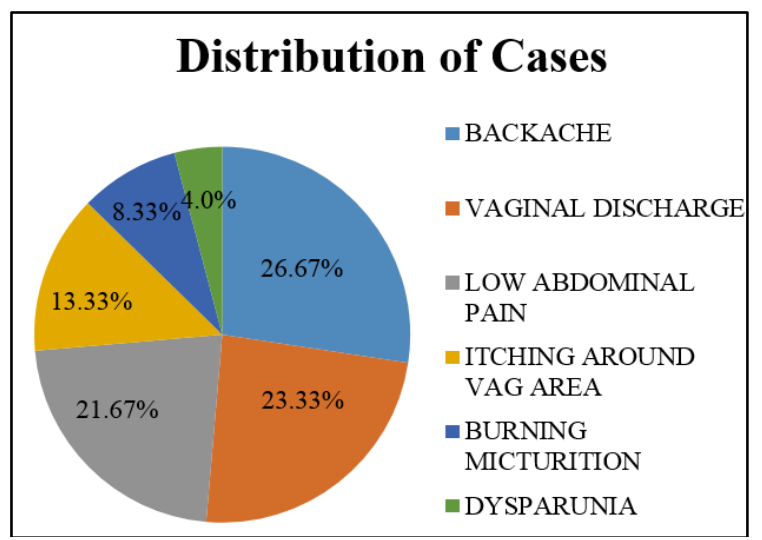

Fig. 1

The predominant clinical feature was lower backache $(26.6 \%)$, discharge per vaginum $(23.3 \%)$, pain in lower abdomen (21.6\%), while the incidence of itching around vaginal area, burning micturition was $13.3 \%$ and $8.3 \%$ respectively. Dysparunia was found in 45 women.

Patients were treated with appropriate antibiotics. After completion of treatment for RTI/STI, they were followed and found that their symptoms were relieved. 


\section{Discussion}

The present study shows that the prevalence of RTI is about 60\% (300/500) in patients attending Obst Gynaec OPD. Out of these 53.41 were having symptoms suggestive of RTI while $46.6 \%$ were asymptomatic. This reflects that the women having complaints of genital infections had kept the history hidden from family members, majority of women gave history of symptoms suggestive of RTI after asking leading question. Those who gave history of symptoms suggestive of RTIs, were having disease progressed to non bearing extent. Previous community based studies shows prevalence between 15\%-80\%. ${ }^{711}$ Sami Ramia at al study result showed prevalence of RTI $(28.2 \%) .{ }^{12}$ Our study shows that highest prevalence of C. albicans was $41 \%$ in pregnant women. ${ }^{13}$

The present study objective was to observe influence of socioeconomic status on RTI. Our study showed that 63.3 of patients with RTI had monthly income of $<10000$ and $36.6 \%$ of patients with RTI had monthly income $>10000$. One study by Dameru et al showed that low income socioeconomic status as a risk factor for RTI. ${ }^{9,14}$

The present study revealed that $59 \%$ patients were Illiterate and $41 \%$ were literate. This shows that literacy does not have any influence on RTI. On the other hand Dameru et al reported that women with informal education had more RTI. Similarity one study conducted by Pravina Kafle et al shows similar result as that of Dameru et al. ${ }^{15}$

In present study $11.2 \%$ patients were having history of previous abortion.

Regarding symptoms, $53.3 \%$ patients were symptomatic while $46.6 \%$ were asymptomatic. Among the symptoms $50 \%$ were having backache which they were thinking non specific. Different types of vaginal discharge was present in $43.7 \%$ patients, while $40.6 \%$ were having pain in lower abdomen. Itching of vulva \& around vagina was present in $25 \%$ cases, burning micturition was the compliant in $15.6 \%$ cases. No one was having genital ulceration or inguinal swelling. One study in Nigeria reported $57.7 \%$ of women had vaginal discharge, vulval itching \& pain in lower abdomen. ${ }^{16}$

The study states that women during reproductive age group must be educated regarding genital hygiene especially during menses. Awareness must be created among women by giving health talks related to reproductive tract infection. The confidence should be build up to come forward and tell any minor complaints also to health care provider so that the conditions are diagnosed early \& treatment can be given at earlier stage, due to which morbidity due to genital infection in the form poor general health, hesitation in talking about genital complaints \& overall ill effect of RTI on their life can be minimised.

This study was hospital based so it has limitation. Further community based studies should be extended to all levels of residential areas like slum areas in urban, working women who work as labourers to women who are on higher post, women staying in villages.

\section{Conclusion}

Above study shows that socioeconomic status, literacy play important role in developing RTI/STI. Basic awareness related to RTI should be created among these populations. The most common symptom was backache, vaginal discharge. Health education talks and training of personal and genital hygiene needs to be carried out among rural areas, low socioeconomic group and illiterate population.

\section{References}

1. Howkins and Bourne, Shaws textbook of gynecology ch 11 sexually transmitted diseases $\mathrm{p}-155$.

2. Bany RA, bang AT Bailule m, Choudhary T, Sarmukadam S, Taleo high prevalence of gynecologycal diseases in rural Indian women lancet. 1989;1;285-8

3. Lathak Kanani Sj, Maitra N, Bhattacharya Rv. prevalence of clinically detectable gynaecological morbidity in India. Results of four community based studies. Family welfare. 1997;43;8-16.

4. SA Rizwan, Rama Roth, Gupta Vivek, Nikita, Avaut, Ahmad, Farhad, Silan Vijay, KAp study of STISI RTIS among married women in rural Haryana, Indian Dermatology Online Journal. 2015 jan-feb;6(!):9-12.

5. Low N, Broutet N, Adu_ Sarkodie Y, Barton p, Houssain M, Hawke s (2006) Global control of sexually transmitted infections. Lancet. 368:2001-2006.

6. World Health Organization 2003 Guidelines for the management of sexually transmitted infections. Available:

7. http:/?www.who.int/hiv/sti/en/STIGuidelines2003.pdf. last accessed February 2011.

8. R.P. Ravi and R.A. Kulasekaran, "Care seeking behaviour to accessing services for sexual health problem among womens inrural area of Tamilnadu state in India," Journal of sexually transmitted diseases. vol.2014, article ID292157, 8 pages 2014.

9. K.P. Thekdin, N.K. Patel, K.G. Patel and P.I. Thekdi," Health seeking attitude of women regarding reproductive tract infections in a rural area of Surendranagar district." International journal of research in medical science. 2013;1(4):552-556.

10. P.P Dameru, "Prevalance and factor associated with reproductive tract infections among married women of reproductive age in Nepal." Asian Journal of Medical Science. 2012;2(1)46-49.

11. P.S. Philip, A.I. Benjamin, and P. Sengupta. Prevalence of symptoms suggestive of reproductive tract infections /sexually transmitted infections in women in urban area of Ludhiana. Indian Journal of Sexually Transmitted Diseases. 2012;56,(3):204-209.

12. A. Parashar, B. Gupta, A. Bhardwaj, and R. Sarin, "Prevalence of RTIs among women of reproductive age group in Shimla city,', Indian Journal of Community Medicine. 2006;31(1)15-17.

13. Sami Ramia et al reproductive tract infections (RTIs) among married non-pregnant women living in lowincome suburb of Beirut, Lebanon J infect Dev Ctries. 2012;6(9):680-683.

14. Ibrahim SM, et al, Niger J med 2013 Apr-Jun prevalence of vaginal candidiasis among pregnant women with abnormal vaginal discharge in Maiduguri. 
15. Y.K. Kazi, A.G. Shenoy, G. Velhal, and S.R. Suryawanshi, Reproductive and sexual tract infections among married female youth in an urban slum of Mumbai. National Journal of Community Medicine. 2013;4(1):10-14.

16. Pravina Kafle et al prevalence and factor associated with reproductive tract infections in Gongolia village, Rupandehi district, Nepal advances in public health volume 2016 (2016)

17. Kabiru A. Rabiu, Adeniyi A. Adewunmi, Fatimat M. Akinlusi, and Oluwarotimi I. Akinola. Female reproductive tract infections: understandings and care seeking behaviour among women of reproductive age in logos, Nigeria. BMC women health. 2010;10;8-12.

How to cite this article: Sawant V, Jaiswal S, Desai M. Impact of socioeconomic and demographic factors on reproductive tract infections during reproductive age group (18 - 45) years. Ind J Obstet Gynecol Res. 2018;5(3):353356. 